\title{
Cientifífica
}

http://revistas.udistrital.edu.co/ojs/index.php/revcie/index

\section{METODOLOGÍA DE LA INVESTIGACIÓN EN INGENIERÍA}

Entre los científicos persiste el malentendido, debido a la concepción heredada de la ciencia del siglo XIX, de que la ingeniería es una parte de la ciencia aplicada y que el diseño en ingeniería es solo una especie de investigación científica (a menudo considerada empírica y cíclica). Sin embargo, este ha llevado a generar una actitud negativa hacia la ingeniería y su aprendizaje.

En este sentido, hemos de resaltar que la metodología de la investigación en ingeniería tiene una estructura propia aparte del diseño y el desarrollo ingenieril, que comparte muchas similitudes con la ciencia y están fuertemente entretejidos y mutuamente dependientes. Por otro lado, existen diferencias fundamentales entre la investigación científica y el diseño de ingeniería.

Por lo tanto, se requiere de metodologías específicas para la investigación en ingenierías, debido principalmente a que son procesos basados en modelos estructurales (ciclo de investigación y el ciclo de diseño) que muestran una sorprendente similitud. Las nuevas propuestas epistemológicas basadas en el socioconstructivismo plantean si las diferencias podrían ser solo semánticas o si, por el contrario, se trata de diferencias con carácter más filosófico y epistémico debido al amplio espectro que abarcan las problemáticas propias de la ingeniería.

La metodología de la investigación en ingeniería puede ser muy diversa considerando sus objetos de conocimientos y sus métodos de investigación, los cuales se relacionan con: la ingeniería de requisitos, configuración, gestión, análisis funcional, arquitectura de un sistema, diseño conceptual, evaluación del diseño, toma de decisiones, gestión del cambio de diseño, ingeniería basada en modelos, escalabilidad, innovación y modelos educativos en la formación de ingenieros.

Generalmente, el método de investigación debe plantearse al definir las preguntas de investigación, proponer un método robusto, resolver el problema y validar el método de investigación y los resultados. En este sentido, se hace necesario formular métodos, herramientas y fundamentos teóricos alejados del muy criticado método científico como "única" forma de resolver problemas científicos e ingenieriles.

El número que aquí presentamos reafirma el convencimiento de que es necesario romper con las concepciones erróneas derivadas del positivismo lógico, donde la ingeniería es una ciencia aplicada, para migrar hacia concepciones más adecuadas, donde se reconoce que la metodología de la investigación en ingeniería debe ser considera integradora y compleja.

PhD Adriana Patricia Gallego-Torres

Rubén Gonzales-Crespo

Editor

Comité Editorial 